\title{
Impact of second-trip echoes for space-borne high-pulse-repetition-frequency nadir-looking W-band cloud radars
}

\author{
Alessandro Battaglia ${ }^{1,2,3}$ \\ ${ }^{1}$ Department of Environment, Land and Infrastructure Engineering, Politecnico di Torino, Turin, Italy \\ ${ }^{2}$ Department of Physics and Astronomy, University of Leicester, Leicester, UK \\ ${ }^{3}$ National Centre for Earth Observation, Leicester, UK
}

Correspondence: Alessandro Battaglia (alessandro_battaglia@ polito.it)

Received: 21 July 2021 - Discussion started: 16 August 2021

Revised: 1 November 2021 - Accepted: 4 November 2021 - Published: 13 December 2021

\begin{abstract}
The appearance of second-trip echoes generated by mirror images over the ocean and by multiple scattering tails in correspondence with deep convective cores has been investigated for space-borne nadir-looking W-band cloud radar observations. Examples extracted from the CloudSat radar are used to demonstrate the mechanisms of formation and to validate the modelling of such returns. A statistical analysis shows that, for CloudSat observations, second-trip echoes are rare and appear only above $20 \mathrm{~km}$ (thus easy to remove). CloudSat climatology is then used to estimate the occurrence of second-trip echoes in the different configurations envisaged for the operations of the EarthCARE radar, which will adopt pulse repetition frequencies much higher than the one used by the CloudSat radar in order to improve its Doppler capabilities. Our findings predict that the presence of such echoes in EarthCARE observations cannot be neglected: in particular, over the ocean, mirror images will tend to populate the EarthCARE sampling window with a maximum frequency at its upper boundary. This will create an additional fake cloud cover in the upper troposphere (of the order of $3 \%$ at the top of the sampling window and steadily decreasing moving downwards), and, in much less frequent instances, it will cause an amplification of signals in areas where clouds are already present. Multiple scattering tails will also produce second-trip echoes but with much lower frequencies: less than 1 profile out of 1000 in the tropics and practically no effects at high latitudes. At the moment, level-2 algorithms of the EarthCARE radar do not account for such occurrences. We recommend to properly remove these second-trip echoes and to correct for reflectiv-
\end{abstract}

ity enhancements, where needed. More generally this work is relevant for the design of future space-borne Doppler Wband radar missions.

\section{Introduction}

Thanks to their unique capability of penetrating and profiling cloud and precipitation, space-borne millimetre radars are becoming an essential component of the Global Observing System. This has been widely demonstrated by the Kaband radar on board the GPM mission (Skofronick-Jackson et al., 2016) and by the CloudSat cloud profiling radar (CPR) (Tanelli et al., 2008). New missions are on the horizon: the ESA-JAXA EarthCARE (EC) mission (Illingworth et al., 2015) will deploy a W-band Doppler system, whereas NASA is currently in pre-phase A for the Aerosol and Cloud, Convection and Precipitation (ACCP) Designated Observable (DO) mission, which will carry dual-frequency (Doppler) systems with frequencies ranging from $\mathrm{Ku}$ to $\mathrm{W}$ bands in different orbits (Battaglia et al., 2020; Kumjian et al., 2020). In the next decade, Doppler observations will offer a new perspective in process studies (e.g. in the characterization of convective motions - Kollias et al., 2018) and are expected to improve microphysical retrievals (e.g. in rain by providing a robust estimate of raindrop size - Mróz et al., 2020; Mason et al., 2017 - or in snow by distinguishing between rimed and fluffy snowflakes - Mason et al., 2018). Doppler measurements from low-Earth-orbiting satellites are challenging, because the platform motion combined with the finite 
antenna beamwidth introduces significant Doppler broadening which implies a significant reduction in the medium coherency time. Since Doppler radar measurements are derived from coherent measurements of the phase shifts of successive radar pulses, the time between different pulses, known as the pulse repetition interval (PRI), which is the inverse of the pulse repetition frequency (PRF), must be significantly shorter than the decorrelation time of the medium. In order to fulfil this requirement, radar systems with increasingly high PRFs have been considered (which is also beneficial for the augmented Nyquist range). For instance, the EC CPR is expected to operate a PRF between 6.0 and $7.2 \mathrm{kHz}$ (much higher than the CloudSat PRF, ranging from 3.7 to $4.4 \mathrm{kHz}$ ). However, these benefits come at a price: the reduced unambiguous range, $r_{\mathrm{u}}$, i.e. the maximum distance at which a target can be located to ensure that the backscattered power from that target corresponds to the latest transmitted pulse. This quantity can be computed as $r_{\mathrm{u}}=c /(2 \times \mathrm{PRF})$. The trade-off in the selection of the PRF, also referred to as the "Doppler dilemma", has been known since the early days of radar meteorology (Doviak and Zrnić, 2006), particularly in association with ground-based precipitation scanning radars. For such systems, the need for monitoring precipitation at hundreds of kilometres has posed strong constraints on the PRF selection, and mitigating techniques have been implemented, e.g. Torres et al. (2004). From space, the atmosphere with significant cloud and precipitation targets appears much thinner, with clouds very rarely reaching above $20 \mathrm{~km}$, even in the tropics. A PRF of $7.5 \mathrm{kHz}$, which corresponds to $r_{\mathrm{u}} \approx 20 \mathrm{~km}$, seems right at the edge to avoid significant numbers of second-trip echoes. However two situations, both caused by multiple scattering (MS) events (for a thorough review of the topic see Battaglia et al., 2011), that can produce significant returns from ranges much longer than the surface echo and exceeding the unambiguous range must be considered.

1. Mirror images, i.e. virtual images of atmospheric targets that appear to come from below the surface ( $\mathrm{Li}$ and Nakamura, 2002; Meneghini and Atlas, 1986) and are associated with a reflection of energy from the surface to the target and back to the radar via a second reflection at the surface; mirror images are more prominent over ocean surfaces and with incidence close to nadir; and

2. MS tails (Battaglia and Simmer, 2008; Battaglia et al., 2010, 2014, 2016), i.e. virtual images that appear to be produced below a thick and highly scattering medium and are caused by the bouncing of the electromagnetic radiation within the scattering layer itself. For centimetre and millimetre radars, this typically occurs in correspondence with deep convection and in the presence of large and dense ice particles. A remarkable example of such a phenomenon was observed in CloudSat (Battaglia et al., 2010, Fig. 21) with a MS tail above $-15 \mathrm{dBZ}$ visible all the way from the top of the deep convection located at 18.5 to $25 \mathrm{~km}$ (the maximum sampling height of the CloudSat CPR).

In this work, we explore the impact of these two phenomena by first investigating their frequency in the CloudSat database and then by exploiting the CloudSat dataset to simulate their occurrence in the upcoming EC mission. Section 2 provides a description of the mirror images and the MS tails, as well as their modelling; a discussion of the mechanism of how these signals produce and are expected to produce secondtrip echoes for the CloudSat and EC CPRs; and examples extracted from the CloudSat database. In Sect. 4, a full year of CloudSat data are exploited to predict the occurrence of second-trip echoes associated with mirror images and multiple scattering tails for the EC CPR. Conclusions and future work are presented in Sect. 5 .

\section{Mirror images and their simulation}

The modelling of the return of mirror images is thoroughly described in Meneghini and Atlas (1986) and Meneghini and Kozu (1990). The return power from the mirror, $P_{\mathrm{r}}\left(r_{\mathrm{m}}\right)$, appears to come from a range $r_{\mathrm{m}}=r_{\mathrm{t}}+2 H_{\mathrm{t}}$, where $r_{\mathrm{t}}$ is the range of the target, and $H_{\mathrm{t}}$ is its height above the surface and is related to the return power from the target itself, $P_{\mathrm{r}}\left(H_{\mathrm{t}}\right)$, by

$$
\begin{aligned}
& 10 \log _{10}\left[P_{\mathrm{r}}\left(r_{\mathrm{m}}\right)\right]=10 \log _{10}\left[P_{\mathrm{r}}\left(r_{\mathrm{t}}\right)\right]-4 A_{\text {surface } \rightarrow \text { target }} \\
& +10 \log _{10}\left[\frac{\left(H_{\text {sat }}-H_{\mathrm{t}}\right)^{2} \Gamma^{4} \sigma_{0}}{\sigma_{0} H_{\text {sat }}^{2}+11.04 \Gamma^{2} \frac{H_{\mathrm{t}}^{2}}{\theta_{3 \mathrm{~dB}}^{2}}}\right],
\end{aligned}
$$

where $H_{\text {sat }}$ is the height of the satellite, $\theta_{3 \mathrm{~dB}}$ is the antenna $3 \mathrm{~dB}$ beamwidth, $\sigma_{0}$ is the surface-normalized backscattering cross section, $\Gamma$ is its Fresnel reflection coefficient and $A_{\text {surface } \rightarrow \text { target }}$ is the one-way attenuation encountered in the path between the surface and the target expressed in decibel $(\mathrm{dB})$. Therefore, the mirror return is reduced by two factors:

1. the attenuation due to the extra path (four times the path from the target to the surface) expressed by the second term on the right-hand side of Eq. (1); and

2. an additional "mirror loss factor", the third term on the right-hand side of Eq. (1), which accounts for the specular reflection property of the surface, its backscattering cross section and the geometry of observation.

When considering the parameters of the EarthCARE radar, the mirror loss factor assume the values plotted in Fig. 1 for characteristic values of $\sigma_{0}$ between 5 and $18 \mathrm{~dB}$ and target altitudes from 0 up to $14 \mathrm{~km}$. Very close to the surface, the mirror loss is at a minimum level and converges to the value $10 \log _{10}\left(\Gamma^{4}\right)=-8.5$ and is independent of $\sigma_{0}$ and the observation geometry. Generally for water surfaces, this limit 


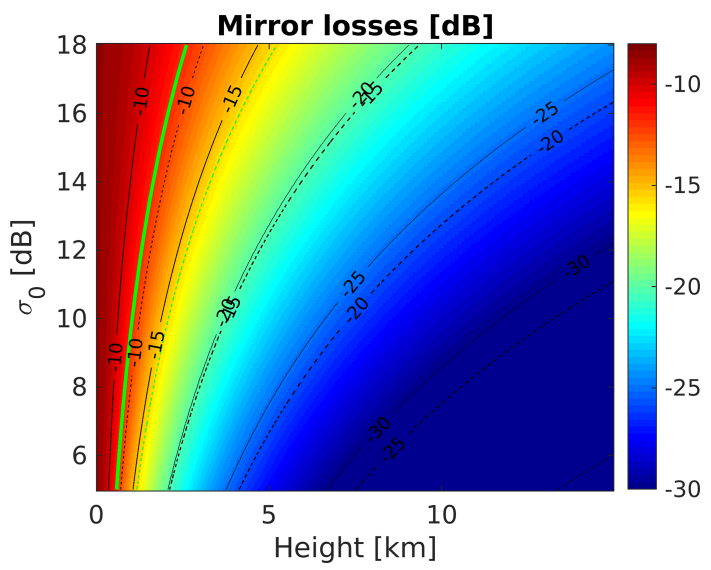

Figure 1. Mirror loss factor derived from Eq. (1) as a function of $H_{\mathrm{t}}\left(x\right.$ axis) and $\sigma_{0}$ ( $y$ axis) for the EarthCARE (colour shading and continuous black contour lines) and the CloudSat (dashed black contour lines) $94 \mathrm{GHz}$ cloud profiling radars for a water surface at $10^{\circ} \mathrm{C}(\Gamma=0.608)$. Values of $H_{\text {sat }}$ equal 400 and $705 \mathrm{~km}$ and those of $\theta_{3 \mathrm{~dB}}$ equal $0.095^{\circ}$ and $0.1085^{\circ}$ and have been used for the EarthCARE and CloudSat configuration, respectively. The continuous (dashed) green line corresponds to the values where the two addends in the denominator of the third term on the right-hand side of Eq. (1) are equal for the EarthCARE (CloudSat) configuration.

value ranges between -7.6 and $-10 \mathrm{~dB}$ since $\Gamma$ assumes values between 0.56 and 0.64 with temperature between 0 and $20^{\circ} \mathrm{C}$, respectively. Note that this (minimum) mirror loss is larger in magnitude than at smaller frequencies, e.g. $-4.4 \mathrm{~dB}$ at Ku and Ka bands (Li and Nakamura, 2002). When increasing the height of the target, the mirror losses tend to increase and increasingly show a dependence on $\sigma_{0}$. This tendency depends on the relative weight of the two terms in the denominator of the third term on the right-hand side of Eq. (1): if the first term dominates, the mirror loss becomes equal to $\Gamma^{4}$; otherwise, it becomes proportional to $\sigma_{0}$, to $\Gamma^{2}$, to $\theta_{3 \mathrm{~dB}}^{2}$ and to the square of the ratio $H_{\text {sat }} / H_{\mathrm{t}}$. The green lines in Fig. 1 highlight where the two terms are equal for the two configurations considered in this paper. Because of the different satellite heights and radar beamwidths, the mirror losses for the EarthCARE radar tend to be higher than for the CloudSat radar (compare dashed and continuous black contour lines), with the weight of the first term being generally larger in CloudSat configuration when the same $\sigma_{0}$ and $H_{\mathrm{t}}$ values are considered (compare green lines).

When passing to reflectivities expressed in decibel relative to $Z$ (dBZ), Eq. (1) becomes

$$
\begin{gathered}
Z\left(r_{\mathrm{m}}\right)=Z\left(r_{\mathrm{t}}\right)+20 \log _{10} \frac{r_{\mathrm{m}}}{r_{\mathrm{t}}}-4 A_{\text {surface } \rightarrow \text { target }} \\
+10 \log _{10}\left[\frac{\left(H_{\mathrm{sat}}-H_{\mathrm{t}}\right)^{2} \Gamma^{4} \sigma_{0}}{\sigma_{0} H_{\mathrm{sat}}^{2}+11.04 \Gamma^{2} \frac{H_{\mathrm{t}}^{2}}{\theta_{3 \mathrm{~dB}}^{2}}}\right],
\end{gathered}
$$

with a slight amplification term on the right-hand side due to the difference in ranges between $r_{\mathrm{t}}$ and $r_{\mathrm{m}}$. Though the mirror losses can be quite substantial (up to $-30 \mathrm{~dB}$ but more typical values are in the range between -10 and $-25 \mathrm{~dB}$ ) it is clear that, because of the enhanced sensitivities of Wband radars, they are not sufficient to push the mirror signals below the noise level $(-35$ and $-29 \mathrm{dBZ}$ for EarthCARE and CloudSat, respectively). For instance, when considering strongly reflecting ice clouds (15-20 dBZ) located at around $10 \mathrm{~km}$ in the EarthCARE configuration, a total reduction of more than $50-55 \mathrm{~dB}$ is needed to be sure that such cloud will not produce second-trip echoes. Since gas attenuation never exceeds $8-9 \mathrm{~dB}$ two ways even in a very humid and warm atmosphere, this requires additional contributions from hydrometeor attenuation. If such extra attenuation is not present (no low/mid-level clouds), then a mirror image is likely to cause second-trip echoes in typical conditions of operation of space-borne $\mathrm{W}$-band radars.

\subsection{Example of mirror images in CloudSat data}

This situation is epitomized by the example of a mirror image producing second-trip echo for the CloudSat observations of anvil clouds with a highly reflective core located at about $10 \mathrm{~km}$ (Fig. 2a). The folding mechanism is further explained in Fig. $2 b$ for the reflectivity profile at $-32^{\circ}$ latitude (corresponding to the red line in Fig. 2a). The level-1 CPR product reports that the satellite height is $715 \mathrm{~km}$ and that the PRF is $4.37 \mathrm{kHz}$, which corresponds to an unambiguous range of $34.3 \mathrm{~km}$. By distributing an integer number of these $34.3 \mathrm{~km}$ long unambiguous ranges from the satellite height downwards, the folding window (delimited by the dot-dashed black lines) for this profile is between 29 and $-5.3 \mathrm{~km}$ (but note that CloudSat records data only below 25 and above $-3 \mathrm{~km}$, grey shading). The mirror image corresponding to the reflectivity profile is computed according to Eq. (2) with the value of $\sigma_{0}$ derived according to Tanelli et al. (2008) and the value of the attenuation derived from the gas attenuation profile. The mirror image produces reflectivities roughly $20 \mathrm{~dB}$ lower than the anvil for ranges between -5 and $-12 \mathrm{~km}$ below the surface (red line). When this signal is folded back into the folding window, it produces a signal well above CloudSat sensitivity from 29 down to $22 \mathrm{~km}$ (green squares). This is partially recorded by the radar sampling window, with the measured reflectivities reaching values comparable with the simulated ones (compare green and blue curves). This example gives confidence to the fact that the simulation of the mirror and its folding is producing realistic results.

\subsection{Climatology of second-trip echoes associated with mirror images in CloudSat database}

The presence of second-trip echoes in CloudSat is confirmed statistically by looking at the contour frequency al- 

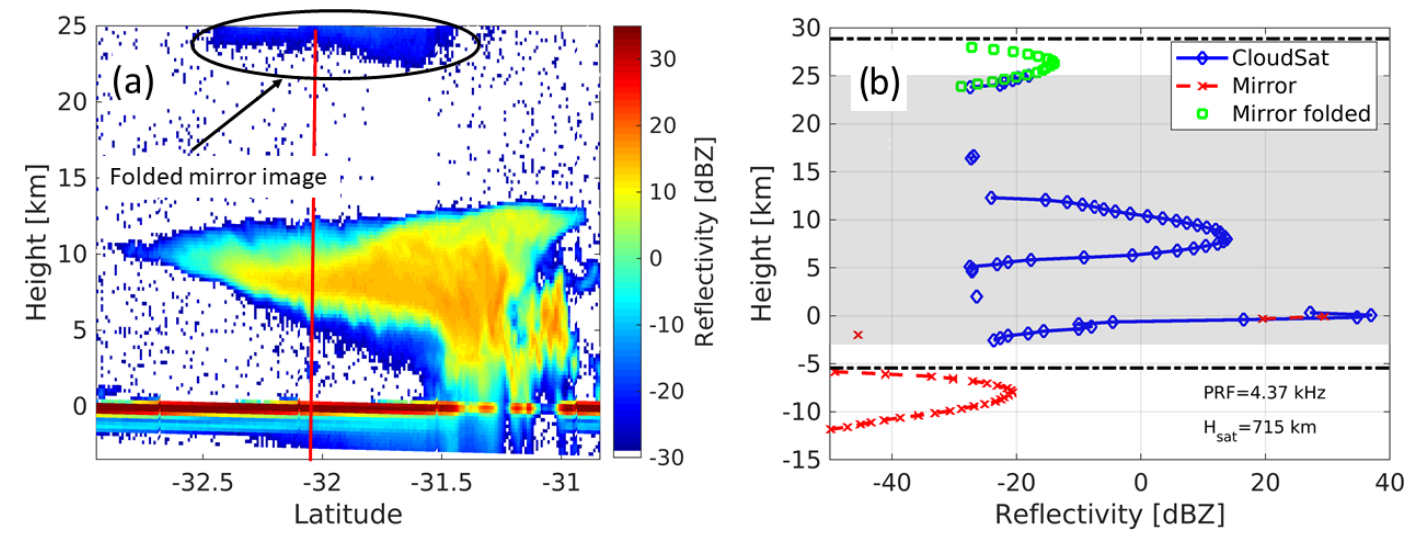

Figure 2. (a) Example of mirror image in CloudSat data produced by a high-reflectivity tropical anvil cloud. The mirror image folds back at heights between 22 and $25 \mathrm{~km}$. (b) Exemplification of the folding mechanism for the profile at $-32^{\circ}$ latitude marked with the red line in panel (a). The dot-dashed black lines delimit the folding ranges; the shaded grey region covers the CloudSat data window.

titude display (CFAD) of CloudSat CPR data for the full 2008 (Fig. 3a). Here we have only considered profiles over open ocean (land surfaces in fact do not behave like specular surfaces; thus, mirror images are much less pronounced; see Battaglia et al., 2010) with no sea ice (as determined by the CloudSat 2C-PRECIP-COLUMN; Haynes et al., 2009) and not in the presence of convection (as derived from the CloudSat 2B-CLDCLASS product; Sassen and Wang, 2008); this roughly correspond to $51.5 \%$ of the CloudSat profiles globally; $15.2 \%, 91 \%, 68 \%, 48 \%$ and $15.3 \%$ of the CloudSat profiles for the southern high latitudes, southern mid latitudes, the tropical belt, the northern mid latitudes and the northern high latitudes, respectively. The presence of fake clouds between 23 and $25 \mathrm{~km}$ with reflectivities between -28 and $-20 \mathrm{dBZ}$ confirms the presence of second-trip echoes associated with mirror images. Globally, when considering the layer between 19.5 and $21 \mathrm{~km}$ as a reference for returns with no second-trip echoes, this corresponds to fake clouds with a frequency of less than 1 out of 500 CloudSat profiles at $25 \mathrm{~km}$ (Fig. 3b). Note that the occurrences very quickly drop to less than one profile out of one million below $23.5 \mathrm{~km}$. Higher frequencies are registered in the tropical belt (blue line) and in the southern mid latitudes. Because of their location at heights well above the tropopause, it is very easy to flag these clouds and exclude them from further analysis. This can be facilitated even more by the synergistic use of a lidar (Cloud-Aerosol LIdar with Orthogonal Polarization (CALIOP) for the CloudSat CPR and High Spectral Resolution Lidar (HSRL) for the EarthCARE CPR).

\subsection{EarthCARE folding}

EC will adopt substantially higher PRFs than CloudSat, with interlaced low- and high-PRF modes in order to optimize the Doppler performance (Tomiyama et al., 2020). Because of the change of altitude of the satellite along the orbit, roundtrip time will also change along the orbit, and these changes may exceed the PRI. This requires us to design the radar timing via variable PRF so that the radar echo window remains centred within the troposphere. Here to study the effect we only analyse two situations with the satellite always flying at the same orbit $(405 \mathrm{~km})$ :

1. a "low-PRF mode" with a PRF of $6.255 \mathrm{kHz}\left(r_{\mathrm{u}}=\right.$ $24 \mathrm{~km}$ ), a folding interval from 21.6 and $-2.4 \mathrm{~km}$, and a sampling window between 20 and $-1 \mathrm{~km}$; and

2. a "high-PRF mode" with a PRF of $7.35 \mathrm{kHz}\left(r_{\mathrm{u}}=\right.$ $20.4 \mathrm{~km}$ ), a folding interval from 17.5 and $-2.9 \mathrm{~km}$ folding, and a sampling window between 16 and $-1 \mathrm{~km}$.

The same CloudSat profile illustrated in Fig. 2 will fold as depicted in Fig. 4 for these two modes. We can clearly distinguish two situations.

1. The mirror image is folded back into a region with no cloud (as detected by CloudSat). This will originate additional fake cloud cover; this is the case for the lowPRF mode (Fig. 4a).

2. The mirror image is folded back into a region where there is already a cloud; this is the case for the highPRF mode (Fig. 4b) where part of the second-trip echo overlaps with the first-trip echo. In this case, the mirror image will both slightly extend the cloud cover above the real cloud top and modify the value of the real cloud reflectivity but only if the signal-to-mirror ratio (SMR) is small (e.g. if $S M R=0 \mathrm{~dB}$ like at $11.3 \mathrm{~km}$, it will double the signal).

In both cases the situation looks much more ambiguous than the second-trip echo generated by CloudSat, and it will require much more effort to be properly identified. 

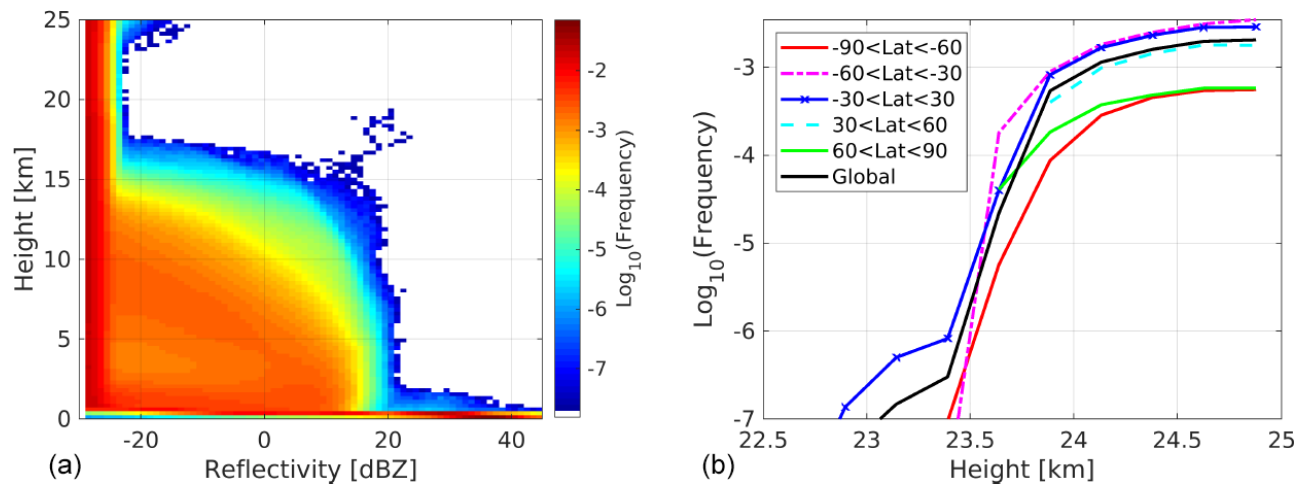

Figure 3. (a) CFAD of CloudSat reflectivities over the ice-free ocean with no convection for 2008. The anomalous presence of clouds between 23 and $25 \mathrm{~km}$ with reflectivities between -28 and $-20 \mathrm{dBZ}$ is due to second-trip echoes associated with mirror images. (b) Frequency of second-trip echoes above $22 \mathrm{~km}$ for different latitudinal bands derived from the CFAD subtracting the "noise floor" as computed by averaging altitudes between 19.5 and $20.75 \mathrm{~km}$.
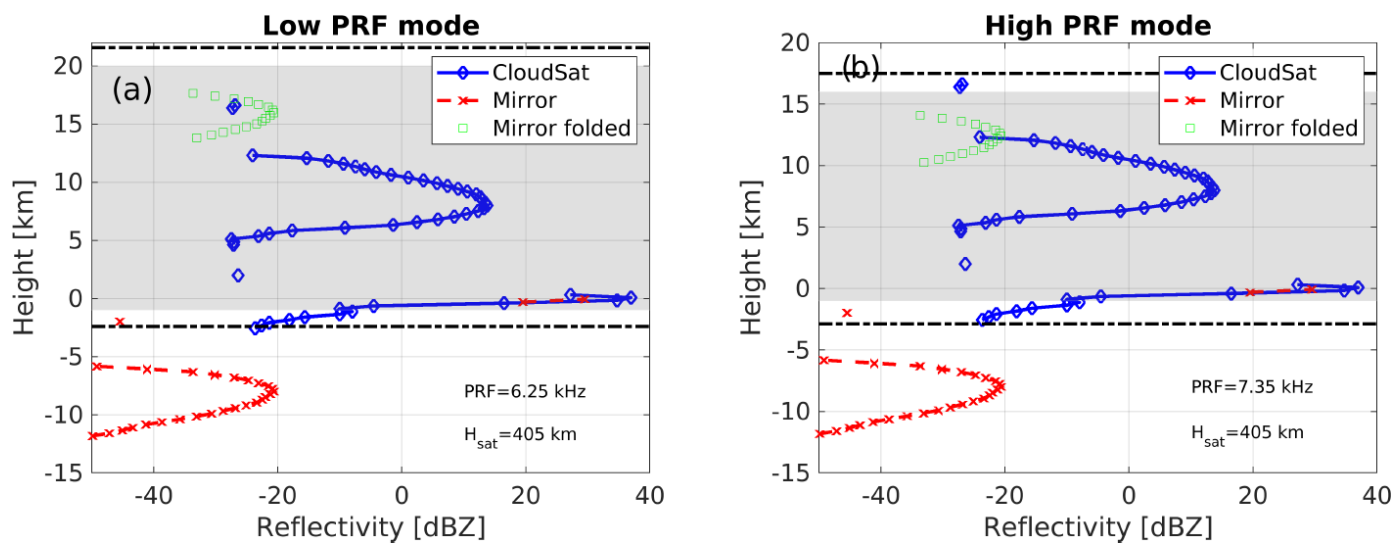

Figure 4. Example of how the mirror image is expected to fold for the low-PRF mode (a) and high-PRF mode (b) for the EarthCARE CPR in correspondence with the same CloudSat profile illustrated in Fig. 2b. The dot-dashed black lines delimit the folding ranges; the shaded grey region covers the EarthCARE sampling window for the two modes.

\section{Multiple scattering tails and their simulation}

In the presence of deep convection, MS can be so strong that it can generate returns from ranges well below the surface by producing long tails, a phenomenon known as pulse stretching (Hogan and Battaglia, 2008). The typical profiles in such conditions tend to peak close to $20 \mathrm{dBZ}$ at very high altitudes $(>10 \mathrm{~km}$ ) and then have reflectivities decreasing towards the ground. Very often the surface return peaks corresponding to the surface tend to disappear. A case study is shown in Fig. 5 for a deep convective system that occurred on 11 January 2008 over the Indian Ocean and north of Western Australia. The system reaches above $17 \mathrm{~km}$ in height; the convective core, where very strong MS clearly occurs, extends for almost $25 \mathrm{~km}$ along track from -15.2 to $-14.95^{\circ}$. In that region, when focusing on surface ranges, the surface peak always disappears, while the reflectivity signal goes below the minimum detectable level only on the right flank, and it maintains values as high as $-6 \mathrm{dBZ}$ in the centre of the core.
The slopes of all the reflectivity profiles in the core present very low values and tend to become smaller when getting closer to the surface where they can reach values lower than $1 \mathrm{~dB} \mathrm{~km}^{-1}$. This is clearly incompatible with single scattering which predicts such low values already in correspondence with rainfall rates of $0.6 \mathrm{mmh}^{-1}$ (Matrosov et al., 2008).

In a very crude approximation, we have extrapolated the MS tail by using an interpolation of the decreasing part of the measured reflectivity profile (excluding the surface peak, if present) by an exponential function of the form:

$Z_{\mathrm{fit}}(z)=A+B \exp (C z)$,

with $A, B$ and $C$ as fitting parameters; however, we have altered this function to a line with slope of $1.5 \mathrm{~dB} \mathrm{~km}^{-1}$ once the slope of the exponential function surpasses this limit. An example of the fitting procedure is demonstrated in Fig. 6 where we have used the reflectivity profile corresponding to the black line shown in Fig. 5, acquired by the CloudSat 


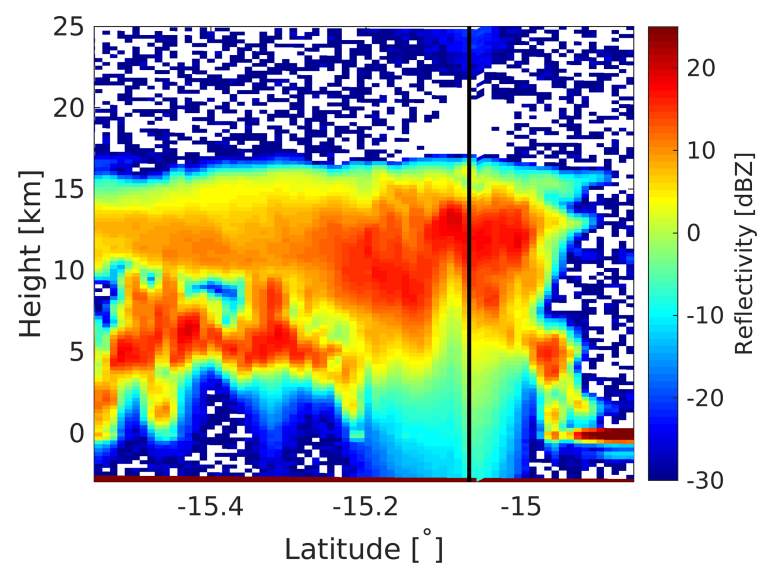

Figure 5. Example of second-trip echoes, visible between 22 and $25 \mathrm{~km}$, generated by MS tails in CloudSat reflectivity vertical profile observations of a deep convective system. The satellite is moving southward from Indonesia towards Australia over the Indian Ocean.

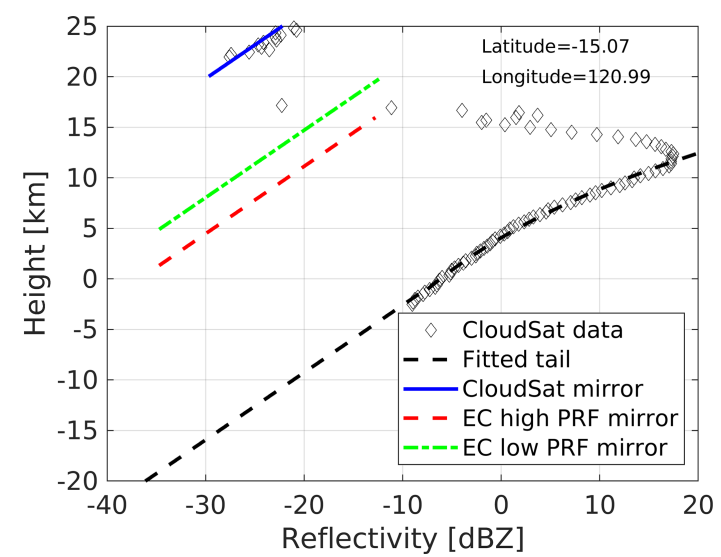

Figure 6. Example of folding of MS tails for the profile corresponding to the black line shown in Fig. 5. The CloudSat reflectivity profile (diamonds) which is sampled only down to $-2.5 \mathrm{~km}$ is extrapolated down to $-20 \mathrm{~km}$ (dashed black line) and then folded back according to the CloudSat unambiguous range (blue line) and the two EarthCARE high- and low-PRF modes (red and green lines, respectively).

radar circa $250 \mathrm{~km}$ from the Dampier Peninsula in Western Australia. The CloudSat reflectivity measurement, plotted with diamonds, clearly indicates the presence of second-trip echoes with reflectivity values between -27.6 and $-21 \mathrm{dBZ}$ between 22 and $25 \mathrm{~km}$. These are well explained if the extrapolated MS tail (dashed black line) is folded back according to the CloudSat satellite height and PRF (blue line). The effect is the generation of a fake cloud, the reflectivity of which remains marginally above the CloudSat minimum sensitivity threshold.

If we fold back the same MS tail by using the EarthCARE high- and low-PRF modes described in Sect. 2.3 the folded signals (red and green lines, respectively) remain above the
EarthCARE minimum sensitivity for a much longer distance than for the CloudSat case but with diverse outcomes: whereas with the low-PRF mode a fake cloud will appear between 17 and $20 \mathrm{~km}$ (the sampling window upper limit), with the high-PRF mode the second-trip echoes will be completely overwhelmed by the first-trip echo and will only marginally modify the sampled signal at $16 \mathrm{~km}$ since the second-trip echo is $15 \mathrm{~dB}$ lower than the first echo signal. This outcome of course depends on the interplay between height of the system, adopted PRF mode and sampling window.

\section{Climatology of second-trip echoes associated with MS tails in CloudSat database}

Convective profiles have been extracted by using the classification of the 2B-CLDCLASS product for the full 2008 CloudSat dataset. Note that here, unlike the mirror image case, both profiles over ocean and over land are considered, and indeed convection is generally stronger over land than over ocean (e.g. Mroz et al., 2017). Circa $1.1 \%$ of all profiles are classified as convective. The corresponding CFAD is depicted in the left panel of Fig. 7. As in Sect. 2.2, second-trip echoes appear at the very top of the CloudSat sampling window above $23 \mathrm{~km}$. The frequency of such echoes as a function of height for different latitudinal bands is shown in the right panel. The frequency is maximized at $25 \mathrm{~km}$ and strongly decreases moving towards the poles. The phenomenon is rare; in fact, even at its maximum (at $25 \mathrm{~km}$ and for the tropical belt) it basically occurs with an absolute frequency of $10^{-3.7}$; i.e. roughly 1 out of 50 profiles conditional to being convective presents a second-trip echo.

\section{Second-trip echoes in EarthCARE observations}

The CloudSat database can be used to predict the occurrence of second-trip echoes associated with mirror images and with multiple scattering tails.

\subsection{Second-trip echoes associated with mirror images}

The CloudSat profiles are used first to simulate mirror images by using Eq. (2) and the EC parameters for satellite height $(405 \mathrm{~km})$ and beamwidth $\left(0.095^{\circ}\right)$; then the mirror images are folded according to the two EC configurations as explained in Sect. 2.3. Only profiles over the ice-free ocean and with no convection are considered. The CFADs for the lowand high-PRF modes are shown in Fig. 8a and b.

Unlike CloudSat, the presence of second-trip echoes is now contaminating the region well below the tropopause for both modes. A primary peak appears in correspondence with the top of the sampling window extending for several kilometres, whereas a secondary peak is present with less pronounced reflectivities at much lower altitudes centred around 11 and $9 \mathrm{~km}$ for the low- and high-PRF modes, respectively. 

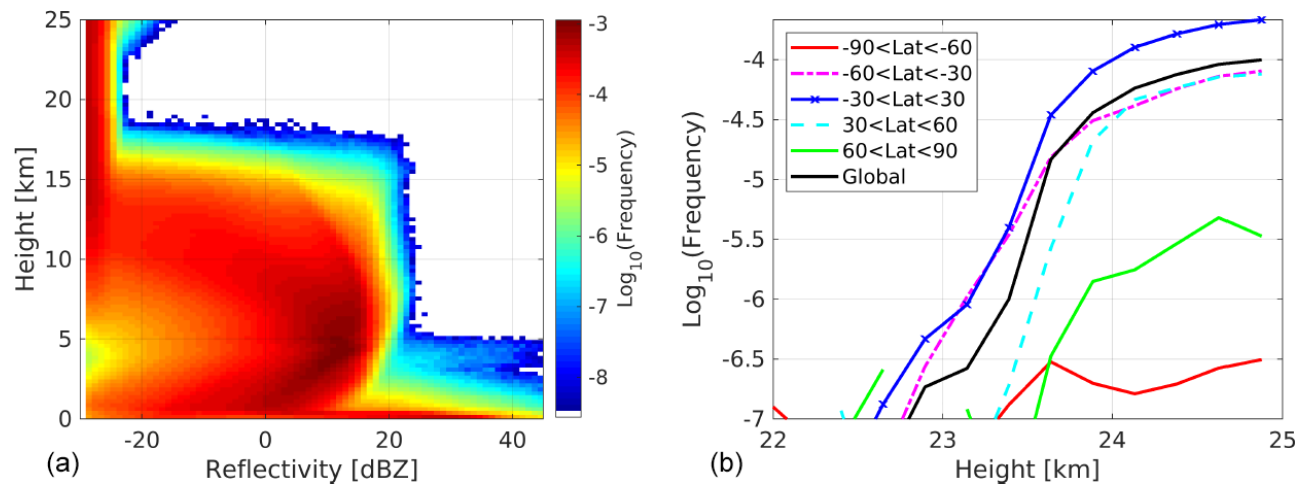

Figure 7. (a) CFAD for CloudSat profiles in convection for 2008 and 2009. The appearance of second-trip echoes is clearly visible above $23 \mathrm{~km}$. (b) Frequency of second-trip echoes for convective profiles as a function of height for different latitudinal bands as indicated in the legend.
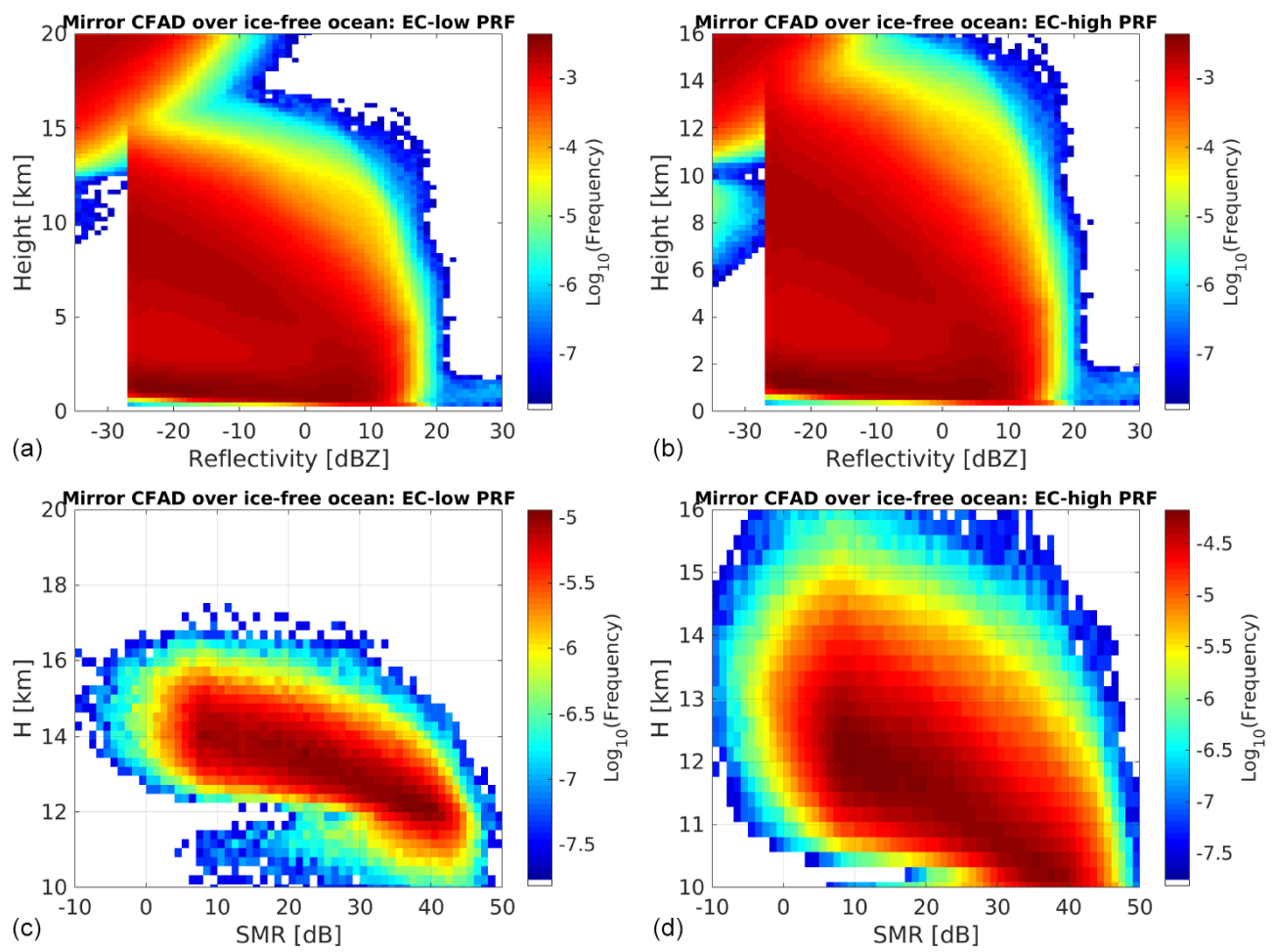

Figure 8. Expected impact of second-trip echoes generated by mirror images in EC observations. (a, b) Simulated CFAD of reflectivities for the low-PRF $(\mathbf{a}, \mathbf{c})$ and high-PRF $(\mathbf{b}, \mathbf{d})$ EarthCARE configurations. (c, d) Same as (a) and (b) for simulated CFAD of signal-to-mirror ratios (SMRs).

Since the reflectivity CFADs represent a cumulative frequency, it is not possible to understand whether the secondtrip echoes occur in correspondence with an already existing cloud or represent a fake cloud. We have therefore produced separated CFADs for second-trip echoes which do not correspond to a signal strong enough to be identified as a cloud by the 2B-CLDCLASS algorithm and which occur concomitantly with a real cloud (not shown). In the latter situation, we have also computed SMRs, i.e. the signal-to-mirror ratios between the cloud true signal and the second-trip echo fake signal; their CFADs are depicted in the bottom panels of Fig. 8. Clearly the majority of the second-trip echoes have strength much lower than the real cloud signals but a nonnegligible portion of second-trip echoes do produce signals which overwhelm the direct cloud signal. This is the case only at heights between 12.5 and $16.5 \mathrm{~km}(10.5$ and $16 \mathrm{~km})$ for the low-PRF (high-PRF) mode.

In Fig. 9 the frequency of second-trip echoes alone (top row) and for coincident second- and first-trip echoes (Fig. 9c and d) for the low-PRF (Fig. 9a and c) and high-PRF (Fig. 9b 

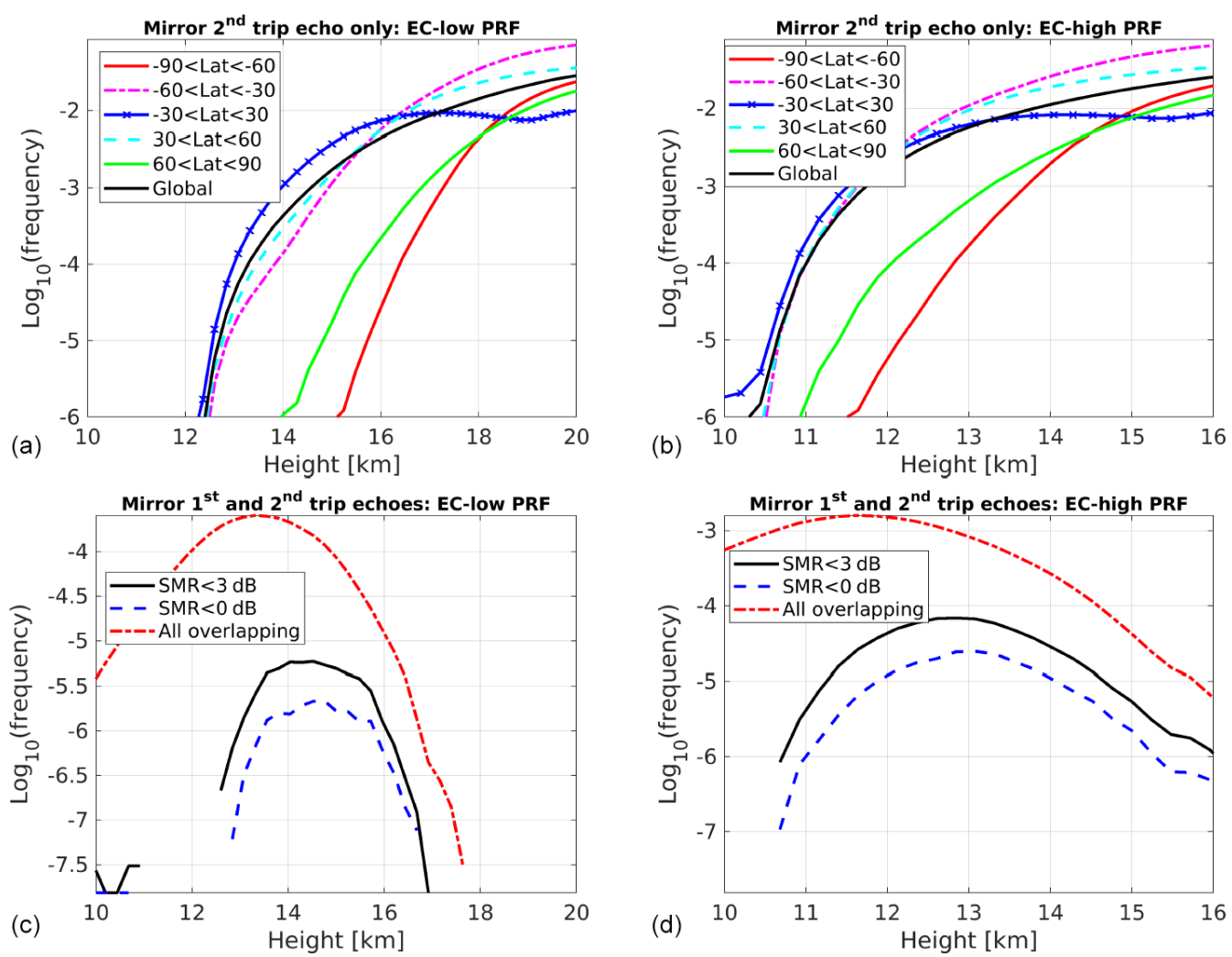

Figure 9. Simulated frequency of second-trip echoes alone (a, b) and for coincident second- and first-trip echoes (c, d) both above the minimum detection threshold for the low-PRF (a, c) and high-PRF (b, d) EarthCARE configurations. In panels (c) and (d), three curves are presented corresponding to signal-to-mirror ratios (SMRs) lower than 0 and $3 \mathrm{~dB}$ (dashed blue and continuous black lines, respectively) or for any SMR (dot-dashed red line).

and d) EC configurations are shown as a function of the height. With the high-PRF mode, the second-trip echoes stretch to lower altitudes (compare Fig. 9a and b). For both modes, at the top of the sampling window, the expected absolute frequency of such instances is about $3 \%$ globally (or roughly $6 \%$ over the ice-free ocean). This frequency is rapidly decreasing to less than $0.1 \%$ at $14.5 \mathrm{~km}(11.8 \mathrm{~km})$ for the low-PRF (high-PRF) mode.

The frequency of coincident first- and second-trip echoes (Fig. 9) is generally much lower, peaking at around 13.5 and $11.5 \mathrm{~km}$ for the low- and high-PRF modes, respectively. These second-trip echoes will enhance the cloud reflectivity signal but in a perceptible way only when the SMR is lower than $3 \mathrm{~dB}$. This happens with frequencies less than $10^{-5.2}$ and $10^{-4.1}$ even in correspondence with the height and the highest number of occurrences $(14.2$ and $12.8 \mathrm{~km})$ for the low- and high-PRF mode, respectively.

\subsection{Second-trip echoes associated with multiple scattering tails}

A similar procedure has been adopted to simulate second-trip echoes associated with MS tails. Out of profiles classified as convective by the 2B-CLDCLASS product only those with a surface return lower than $0 \mathrm{dBZ}$ and reflectivity in the ice layer exceeding $14 \mathrm{dBZ}$ are used as candidates to produce MS tails. Only $1.1 \%$ of the profile is classified as convective, and only $0.07 \%$ fulfils the previous MS tail condition. These profiles are also strongly concentrated in the tropics $(86 \%)$, with much fewer (5\% and 9\%) in the southern and northern mid latitudes and extremely scant percentages in the northern high latitudes $(0.2 \%)$. No profiles are found in the southern high latitudes.

The fitting procedure described in Sect. 3 is used to extrapolate a tail which is then folded according to the two EC modes (Sect. 2.3). No MS tail is produced otherwise. As before, CFADs of reflectivities and SMR for the two modes are produced (Fig. 10). Unlike CloudSat (compare with Fig. 7) and similarly to what is seen with the mirror images (Fig. 8), now there is a considerable overlap between first- and second-trip echoes. In this case, as Fig. 10c and $\mathrm{d}$ shows, any significant overlap between first- and secondtrip echoes is practically absent in the low-PRF mode and marginally present only between 13 and $16 \mathrm{~km}$ in the highPRF mode, where very rarely the SMRs are smaller than $3 \mathrm{~dB}$. 

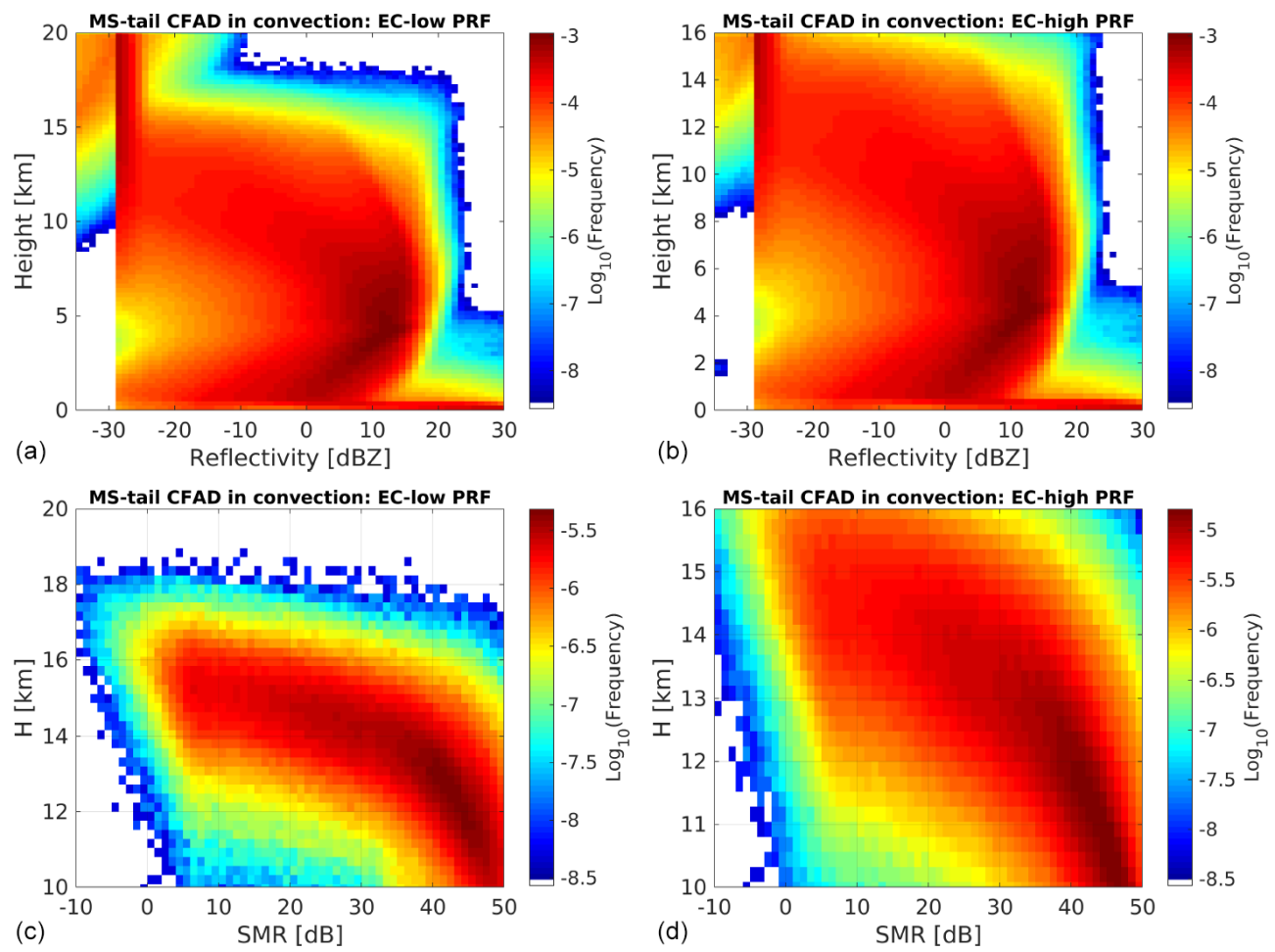

Figure 10. Same as Fig. 8 for the second-trip echoes generated by MS tails.
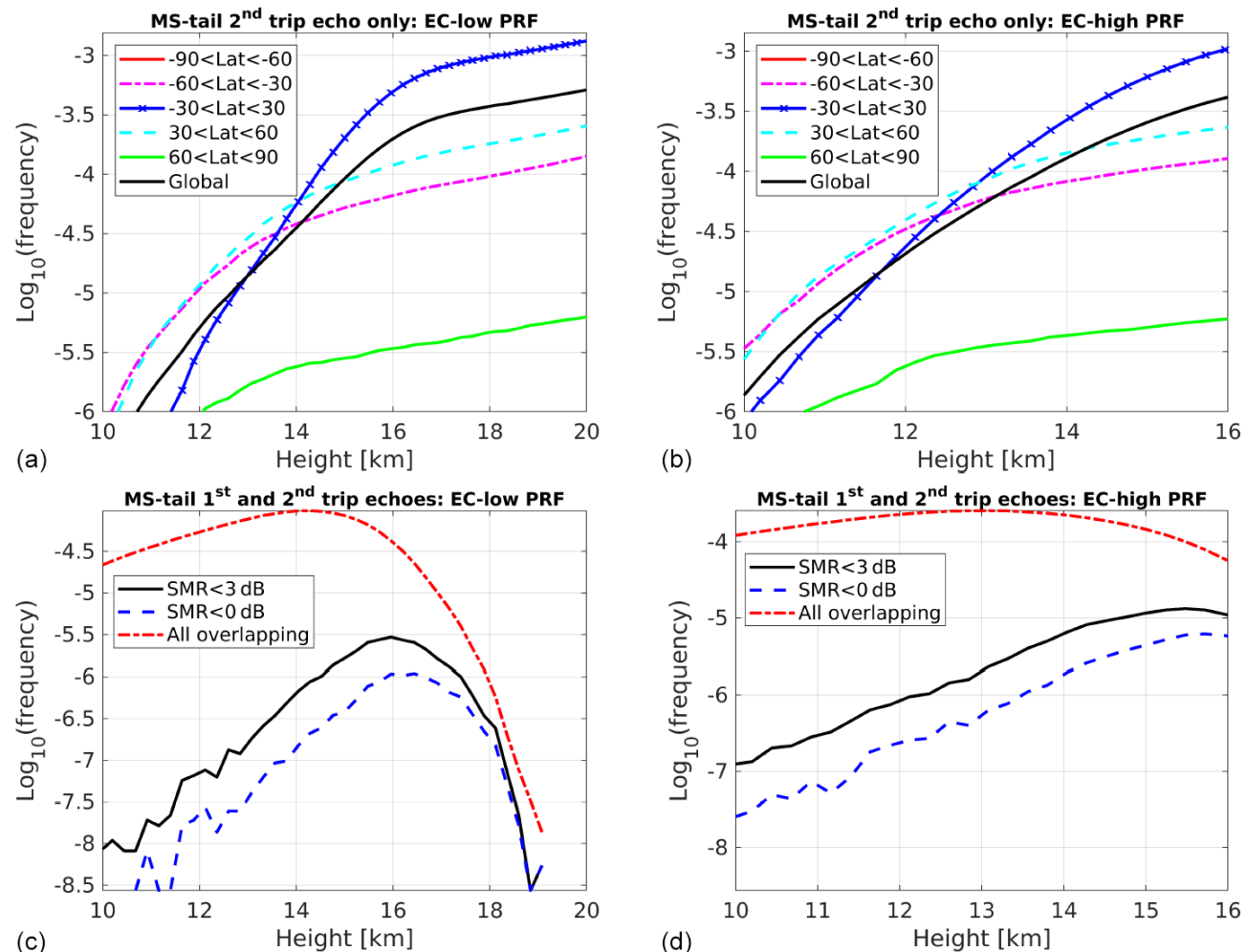

Figure 11. Same as Fig. 9 for the second-trip echoes generated by MS tails. 
This is confirmed by Fig. 11: the most prominent effect associated with MS tails is indeed the appearance of fake clouds with frequencies exceeding 1 out of 3000 profiles at the top of the sampling window for both EC modes. The polar regions (and particularly the Southern Hemisphere) have a scarcity of such events; on the other hand, in the tropics (blue line) the occurrence of such events exceeds 1 out of 1000 cases. For the low-PRF mode (high-PRF mode) heights with the highest occurrences, only 1 profile out of circa 300000 (100 000) has the potential to produce a second-trip echo due to MS tail that will modify the reflectivity of a real cloud return $(\mathrm{SMR}<3 \mathrm{~dB})$.

\section{Conclusions and future work}

Second-trip echoes generated by mirror images over the ocean and multiple scattering tails in correspondence with deep convective cores can become an issue in W-band cloud radar space-borne observations. In CloudSat observations, they do represent a rarity that tend to appear above $20 \mathrm{~km}$; as a result, such features can be easily screened out, and indeed they have passed almost undetected by the cloud radar community. However things may change for other W-band space-borne system which are envisaged to adopt PRFs much higher than the one used by the CloudSat CPR (from 3.7 to $4.4 \mathrm{kHz}$ ) in order to improve their Doppler capabilities.

In this work CloudSat observations and level-2 products have been used to simulate the impact of second-trip echoes in the upcoming EarthCARE observations. We have used two configurations with a low-PRF $(6.3 \mathrm{kHz})$ and a high-PRF mode $(7.3 \mathrm{kHz})$ as an example of the general behaviour expected for the EC CPR. Our findings show that the presence of such echoes cannot be neglected: in particular, over the ocean, mirror images will tend to populate the EarthCARE sampling window with a maximum frequency at the top of the sampling window. This will create additional fake cloud cover in the upper troposphere (of the order of $3 \%$ at the top of the sampling window and steadily decreasing moving downwards), and, in much less frequent instances, it will cause an amplification of signals in areas where clouds are already present. MS tails will also produce second-trip echoes but with much lower frequencies: less than 1 profile out of 1000 in the tropics and practically no effects at high latitudes.

At the moment, level-2 algorithms of the EarthCARE CPR do not account for such occurrences. They will have to properly remove these second-trip echoes and to correct for reflectivity enhancements, where needed. This task can be facilitated by the fact that the amplitude and location of secondtrip echoes can be predicted. In addition to this, the EC high-spectral-resolution lidar co-located measurements will be able to unambiguously identify fake echoes as well.

This work is relevant for the design of future space-borne Doppler radar missions as well. The use of high-PRF mode aimed at improving Doppler performance (Kollias et al.,
2014; Sy et al., 2014; Hagihara et al., 2021) must be considered cautiously. Multiple PRFs could be adopted to separate first- and second-trip echoes as routinely done for groundbased precipitation radars; however, for low-orbiting satellites, constraints related to the change of altitude of the satellite along the orbit (Tomiyama et al., 2020) or to the specific design of the Doppler measurements (e.g. Durden et al., 2007) may significantly reduce the possible combinations of multiple PRFs. The most straightforward way to solve the Doppler dilemma in space-borne systems remains in our view the use of polarization diversity (Kobayashi et al., 2002; Battaglia et al., 2013; Wolde et al., 2019). The experience with CloudSat clearly demonstrates that, for nadir-looking radars, PRFs of the order of $4 \mathrm{kHz}$ are good enough to reduce the presence of second-trip echoes to mere isolated cases, easy to be spotted, flagged and eliminated when building cloud statistics. For slant-looking radars like that proposed by the Wivern mission (Illingworth et al., 2018), the mirror effect can be completely neglected because of the slant-viewing geometry; MS tails could produce second-trip echoes but likely less than here predicted for EC again because of the viewing geometry.

The current modelling is based on the simple approximation of the mirror image proposed by Meneghini and Atlas (1986). More sophisticated modelling, e.g. based on Monte Carlo methods (Battaglia and Simmer, 2008), could account for contributions from a higher order of scattering as well (which will exacerbate the impact). Specific orbital and variable PRF modelling for the EarthCARE analysis could also be considered, though the overall message is not expected to change. Similarly a better description of the MS tail could be provided by $1 \mathrm{D}$ radiative transfer code (e.g. Hogan and Battaglia, 2008), though it is clear that three-dimensional effects play a role in affecting the strength of the MS tail.

A final consideration is given: since the accurate modelling of the second-trip echoes and their amplitudes requires a proper quantification of the scattering properties of the layers generating the MS tails, of the surface reflectivity and of the attenuation between the mirror target and the ground, the measurements of the second-trip echoes could represent an opportunity, for example, to be exploited for providing additional constraints about the hydrometeor properties. For instance, in (light) rain, mirror echoes could be used to cross check whether the rain attenuation correction algorithm is producing an attenuation profile which is in agreement with the mirror echo shape.

Data availability. All CloudSat data are freely available at http://www.cloudsat.cira.colostate.edu/data-products (last access: 3 December 2021); for the 2B-GEOPROF_R04 data set, please see https://www.cloudsat.cira.colostate.edu/data-products/ 2b-geoprof (last access: 3 December 2021, CloudSat, 2007). Details on the GEOPROF algorithms and structure of the HDFEOS output files can be found in Marchand et al. (2008, 
https://doi.org/10.1175/2007JTECHA1006.1) and the Level 2 GEOPROF Product Process Description and Interface Control Document.

Competing interests. The contact author has declared that there are no competing interests.

Disclaimer. Publisher's note: Copernicus Publications remains neutral with regard to jurisdictional claims in published maps and institutional affiliations.

Acknowledgements. This research used the ALICE High Performance Computing Facility at the University of Leicester.

Review statement. This paper was edited by Maximilian Maahn and reviewed by three anonymous referees.

\section{References}

Battaglia, A. and Simmer, C.: How Does Multiple Scattering Affect the Spaceborne W-Band Radar Measurements at Ranges Close to and Crossing the Sea-Surface Range?, IEEE T. Geosci. Remote, 46, 1644-1651, https://doi.org/10.1109/TGRS.2008.916085, 2008.

Battaglia, A., Tanelli, S., Kobayashi, S., Zrnic, D., Hogan, R. J., and Simmer, C.: Multiple-scattering in radar systems: A review, J. Quant. Spectrosc. Ra., 111, 917-947, https://doi.org/10.1016/j.jqsrt.2009.11.024, 2010.

Battaglia, A., Augustynek, T., Tanelli, S., and Kollias, P.: Multiple scattering identification in spaceborne W-band radar measurements of deep convective cores, J. Geophys. Res., 116, D19201, https://doi.org/10.1029/2011JD016142, 2011.

Battaglia, A., Tanelli, S., and Kollias, P.: Polarization Diversity for Millimeter Spaceborne Doppler Radars: An Answer for Observing Deep Convection?, J. Atmos. Ocean. Tech., 30, 2768-2787, https://doi.org/10.1175/JTECH-D-13-00085.1, 2013.

Battaglia, A., Tanelli, S., Heymsfield, G. M., and Tian, L.: The Dual Wavelength Ratio Knee: A Signature of Multiple Scattering in Airborne Ku-Ka Observations, J. Appl. Meteorol. Clim., 53, 1790-1808, https://doi.org/10.1175/JAMC-D-13-0341.1, 2014.

Battaglia, A., Mroz, K., Tanelli, S., Tridon, F., and Kirstetter, P.-E.: Multiple-Scattering-Induced "Ghost Echoes" in GPM DPR Observations of a Tornadic Supercell, J. Appl. Meteorol. Clim., 55, 1653-1666, https://doi.org/10.1175/JAMC-D-15-0136.1, 2016.

Battaglia, A., Kollias, P., Dhillon, R., Roy, R., Tanelli, S., Lamer, K., Grecu, M., Lebsock, M., Watters, D., Mroz, K., Heymsfield, G., Li, L., and Furukawa, K.: Spaceborne Cloud and Precipitation Radars: Status, Challenges, and Ways Forward, Rev. Geophy., 58, e2019RG000686, https://doi.org/10.1029/2019RG000686, 2020.

CloudSat: 2B-GEOPROF_R04. Subset: 2007-2010, CloudSat Data Processing Center [data set], available at: https://www.cloudsat. cira.colostate.edu/data-products/2b-geoprof (last access: 3 December 2021), 2007.

Doviak, R. J. and Zrnić, D. S.: Doppler Radar and Weather Observations, 2nd edn., Dover Books on Engineering, Dover, Mineiola, NY, 2006.

Durden, S. L., Siqueira, P. R., and Tanelli, S.: On the Use of Multiantenna Radars for Spaceborne Doppler Precipitation Measurements, IEEE T. Geosci. Remote S., 4, 181-183, https://doi.org/10.1109/LGRS.2006.887136, 2007.

Hagihara, Y., Ohno, Y., Horie, H., Roh, W., Satoh, M., Kubota, T., and Oki, R.: Assessments of Doppler Velocity Errors of EarthCARE Cloud Profiling Radar Using Global Cloud System Resolving Simulations: Effects of Doppler Broadening and Folding, IEEE T. Geosci. Remote, 1-9, https://doi.org/10.1109/TGRS.2021.3060828, 2021.

Haynes, J. M., L'Ecuyer, T. S., Stephens, G. L., Miller, S. D., Mitrescu, C., Wood, N. B., and Tanelli, S.: Rainfall retrieval over the ocean with spaceborne W-band radar, J. Geophys. Res., 114, D00A22, https://doi.org/10.1029/2008JD009973, 2009.

Hogan, R. J. and Battaglia, A.: Fast Lidar and Radar MultipleScattering Models. Part II: Wide-Angle Scattering Using the Time-Dependent Two-Stream Approximation, J. Atmos. Sci., 65, 3636-3651, https://doi.org/10.1175/2008JAS2643.1, 2008.

Illingworth, A. J., Barker, H. W., Beljaars, A., Ceccaldi, M., Chepfer, H., Clerbaux, N., Cole, J., Delanoë, J., Domenech, C., Donovan, D. P., Fukuda, S., Hirakata, M., Hogan, R. J., Huenerbein, A., Kollias, P., Kubota, T., Nakajima, T., Nakajima, T. Y., Nishizawa, T., Ohno, Y., Okamoto, H., Oki, R., Sato, K., Satoh, M., Shephard, M. W., Velázquez-Blázquez, A., Wandinger, U., Wehr, T., and van Zadelhoff, G.-J.: The EarthCARE Satellite: The Next Step Forward in Global Measurements of Clouds, Aerosols, Precipitation, and Radiation, B. Am. Meteorol. Soc., 96, 1311-1332, https://doi.org/10.1175/BAMS-D-12$00227.1,2015$

Illingworth, A. J., Battaglia, A., Bradford, J., Forsythe, M., Joe, P., Kollias, P., Lean, K., Lori, M., Mahfouf, J.-F., Melo, S., Midthassel, R., Munro, Y., Nicol, J., Potthast, R., Rennie, M., Stein, T. H. M., Tanelli, S., Tridon, F., Walden, C. J., and Wolde, M.: WIVERN: A New Satellite Concept to Provide Global InCloud Winds, Precipitation, and Cloud Properties, B. Am. Meteorol. Soc., 99, 1669-1687, https://doi.org/10.1175/BAMS-D-160047.1, 2018.

Kobayashi, S., Kumagai, H., and Kuroiwa, H.: A Proposal of Pulse-Pair Doppler Operation on a Spaceborne Cloud-Profiling Radar in the W Band, J. Atmos. Ocean. Tech., 19, 1294-1306, https://doi.org/10.1175/15200426(2002)019<1294:APOPPD>2.0.CO;2, 2002.

Kollias, P., Tanelli, S., Battaglia, A., and Tatarevic, A.: Evaluation of EarthCARE Cloud Profiling Radar Doppler Velocity Measurements in Particle Sedimentation Regimes, J. Atmos. Ocean. Tech., 31, 366-386, https://doi.org/10.1175/JTECH-D11-00202.1, 2014.

Kollias, P., Battaglia, A., Tatarevic, A., Lamer, K., Tridon, F., and Pfitzenmaier, L.: The EarthCARE cloud profiling radar (CPR) doppler measurements in deep convection: challenges, postprocessing, and science applications, in: Remote Sensing of the Atmosphere, Clouds, and Precipitation VII, edited by: Im, E. and Yang, S., International Society for Optics and Photonics, SPIE, 10776, 57-68, https://doi.org/10.1117/12.2324321, 2018. 
Kumjian, M. R., Gutierrez, R., Soderholm, J. S., Nesbitt, S. W., Maldonado, P., Luna, L. M., Marquis, J., Bowley, K. A., Imaz, M. A., and Salio, P.: Gargantuan Hail in Argentina, B. Am. Meteorol. Soc., 101, E1241-E1258, https://doi.org/10.1175/BAMSD-19-0012.1, 2020.

Li, J. and Nakamura, K.: Characteristics of the Mirror Image of Precipitation Observed by the TRMM Precipitation Radar, J. Atmos. Ocean. Tech., 19, 145-158, https://doi.org/10.1175/15200426(2002)019, 2002.

Marchand, R., Mace, G. G., Ackerman, T., and Stephens, G.: Hydrometeor Detection Using Cloudsat-An Earth-Orbiting 94GHz Cloud Radar, J. Atmos. Ocean. Tech., 25, 519-533, https://doi.org/10.1175/2007JTECHA1006.1, 2008.

Mason, S. L., Chiu, J. C., Hogan, R. J., and Tian, L.: Improved rain rate and drop size retrievals from airborne Doppler radar, Atmos. Chem. Phys., 17, 11567-11589, https://doi.org/10.5194/acp-1711567-2017, 2017.

Mason, S. L., Chiu, C. J., Hogan, R. J., Moisseev, D., and Kneifel, S.: Retrievals of Riming and Snow Density From Vertically Pointing Doppler Radars, J. Geophys. Res.-Atmos., 123, 1380713834, https://doi.org/10.1029/2018JD028603, 2018.

Matrosov, S. Y., Battaglia, A., and Rodriguez, P.: Effects of Multiple Scattering on Attenuation-Based Retrievals of Stratiform Rainfall from CloudSat, J. Atmos. Ocean. Tech., 25, 2199-2208, https://doi.org/10.1175/2008JTECHA1095.1, 2008.

Meneghini, R. and Atlas, D.: Simultaneous Ocean Cross Section and Rainfall Measurements from Space with a Nadir-Looking Radar, J. Atmos. Ocean. Tech., 3, 400-413, https://doi.org/10.1175/15200426(1986)003<0400:SOCSAR>2.0.CO;2, 1986.

Meneghini, R. and Kozu, T.: Spaceborne weather radar, Artech House, ISBN 9780890063828, 1990.

Mroz, K., Battaglia, A., Lang, T. J., Cecil, D. J., Tanelli, S., and Tridon, F.: Hail-Detection Algorithm for the GPM Core Observatory Satellite Sensors, J. Appl. Meteorol. Clim., 56, 1939-1957, https://doi.org/10.1175/JAMC-D-16-0368.1, 2017.

Mróz, K., Battaglia, A., Kneifel, S., D’Adderio, L. P., and Dias Neto, J.: Triple-frequency Doppler retrieval of characteristic raindrop size, Astr. Soc. P., 7, e2019EA000 789, https://doi.org/10.1029/2019EA000789, 2020.
Sassen, K. and Wang, Z.: Classifying clouds around the globe with the CloudSat radar: 1-year of results, Geophys. Res. Lett., 35, L04805, https://doi.org/10.1029/2007GL032591, 2008.

Skofronick-Jackson, G., Petersen, W., Berg, W., Kidd, C., Stocker, E., Kirschbaum, D., Kakar, R., Braun, S., Huffman, G., Iguchi, T., Kirstetter, P., Kummerow, C., Meneghini, R., Oki, R., Olson, W., Takayabu, Y., Furukawa, K., and Wilheit, T.: The Global Precipitation Measurement (GPM) Mission for Science and Society, B. Am. Meteorol. Soc., 98, 1679-1695, https://doi.org/10.1175/BAMS-D-15-00306.1, 2016.

Sy, O. O., Tanelli, S., Takahashi, N., Ohno, Y., Horie, H., and Kollias, P.: Simulation of EarthCARE Spaceborne Doppler Radar Products Using Ground-Based and Airborne Data: Effects of Aliasing and Nonuniform Beam-Filling, IEEE T. Geosci. Remote, 52, 1463-1479, https://doi.org/10.1109/TGRS.2013.2251639, 2014.

Tanelli, S., Durden, S. L., Im, E., Pak, K. S., Reinke, D. G., Partain, P., Haynes, J. M., and Marchand, R. T.: CloudSat's Cloud Profiling Radar After Two Years in Orbit: Performance, Calibration, and Processing, IEEE T. Geosci. Remote, 46, 3560-3573, https://doi.org/10.1109/TGRS.2008.2002030, 2008.

Tomiyama, N., Tomita, E., Furukawa, K., Nakatsuka, H., Seki, Y., Aida, Y., Okada, K., Maruyama, K., Ishii, Y., Ohno, Y., Horie, H., and Satoh, K.: EarthCARE/CPR development status and performance, in: Remote Sensing of Clouds and the Atmosphere XXV, Proc. SPIE, 11531, 109-116, https://doi.org/10.1117/12.2574244, 2020.

Torres, S. M., Dubel, Y. F., and Zrnic, D. S.: Design, implementation, and demonstration of a staggered PRT algorithm for the WSR-88D, J. Atmos. Ocean. Tech., 21, 1389-1399, 2004.

Wolde, M., Battaglia, A., Nguyen, C., Pazmany, A. L., and Illingworth, A.: Implementation of polarization diversity pulse-pair technique using airborne W-band radar, Atmos. Meas. Tech., 12, 253-269, https://doi.org/10.5194/amt-12-253-2019, 2019. 